UNITED STATES LEPARTMENT OF COMNERCE NATIONAL BUREAU OF STANDARDS WASHI GTON

SPECIFICATION FOR PROVING RINGS FOR CALIBRATING TISTING MACHINES
Letter

Circular

LC548

Supersedin: IC 409

Note - The techical requirements in this specification are identical with those in Letter Circular 409, which it supersedes. The simplified procedure for the recalibration of ring's previously certified is justified by experience in recalibrating proving rings during the past five years.

\title{
I. DEFINITIONS
}

\section{PROVING RING}

A proving ring is an elastic ring, suitable for calibrating a testing machine, in which the deflection of the ring when loaded along a diameter is neasured by means of a micrometer screw and a vibrating reed mounted diametrically in the ring.

\section{READING}

A reading is the value indicated by the micrometer dial when it has been adjusted to contact the vibrating reed.

\section{DEFIECTION}

The deflection of the ring for any load is the difference between the reading for that load and the reading for no load.

4. CALIBRATION F'AC'TOR

The calibration factor for a given deflection is the ratio of the corresponding load to the deflection.

\section{COMPLETE CALIBRATION}

\section{MARKING}

The maker's name, the capacity load, and the serial number of the ring shall be legibly marked upon some part of the instrument. 


\section{MICROMETER DIAL}

(a) The dial of the micrometer shall be of the uniformly graduated type. When successive graduation lines on the dial are set to one fixed index line, the positions of successive graduation lines nearly diametrically opposite referred to another lixed index shall differ from each other by not more than $1 / 20$ of the smallest division of the dial.

(b) The smallest division of the dial shall be not less than 0.05 inch and not more than 0.10 inch.

(c) The width of any graduation line on the dial shall not exceed one tenth of the average distance between adjacent graduation lines.

(d) The width of any index line shall be not less than 0.75 and not more than 1.25 times the average width of the graduation lines on the dial.

\section{OVERLOAD}

The ring shall be overloaded repeatedly to a load of not less than 9 percent nor more than 10 percent in excess of the capacity load. The difference between the no-load reading after the first overload and the no-load reading after any subsequent overload shall not exceed one tenth of one percent of the deflection of the ring under capacity load.

4. STIFFNESS

Under the capacity load the ring shall deflect not less than 0.040 inch.

5. CONSTANCy

(a) Range 1/10 to 2/10 Capacity Load. - The observed deflection of the ring, for an applied load of not less than one tenth nor more than two tenths of the capacity load, shall differ from the average of at least three successive observations for the same applied load by not more than one half of one percent of the deflection for the applied load.

(b) Range 2/10 to Capacity Load. - The observed deflection of the ring, for any applied load not less thar two tenths nor more than the capacity load, shall differ from the average of at least three successive observations for the same applied load by not more than one tenth of one percent of the deflection for the capacity load. 
(c) Disascembling. - The difference between the deflections of the ring, observed before and after the deflection-measuring apparatus is removed and then replaced, shall be not greater than the maxima specified in paragraphs II-5(a) and II-5(b) of this specification, under the loads there specified.

(d) Bearing Blocks. - Compression proving rings shall be loaded through plane, concave, and convex bearing blocks. The deflections of the proving ring for the minimum load and for the raximum load applied by dead weights during the calibration shall be determined when the load is applied to the lower boss of the ring through concave and convex bearing blocks. The differences between the average deflections observed using the concave bearing block and the average deflections observed using a plane bearing block for the same loads shall not exceed the maxima specified in paragraphs II-5(a) and II-5(b) of this specification. The differences between the average deflections observed using the convex bearing block and the average deflections observed using a plane bearing block for the sane loads shall not exceed the maxima specified in paragraphs II-5(a) and II-5(b) of this specification. The concave and convex bearing blccks shall comply with the following requirements:

(1) They shall be steel.

(2) The Brinell numbers shall be not less than 400 and not more than 600.

(3) The radii of curvature of the spherical surfaces shall be not less than 9 feet and not more than 10 feet.

\section{RECAIIBRATION}

1. CONSTANCY

(a) Range 1/10 to 2/10 Capacity Load. - The observed deflection of the ring, for an applied load of not less than one tenth nor more than two tenths of the capacity load, shall differ from the average of at least three successive observations for the same applied load by not more than one half of one percent of the deflection for the applied load.

(b) Range 2/10 to Capacity Load. - The observed deflection of the ring, for any applied load not less than two tenths nor more than the caproity lowa, shall differ from the average of at least three successive observations for the same applied load by not more than one tenth of one percent of the deflection for the capacity load. 
(c) Comparison with Last Calibration. - The observed deflections of the ring during recalibration shall differ from the deflections observed at the time of the last calibration by not more than the maxima specified in paragraphs III-I(a) and III-I(b) of this specification, under the loads there specified.

(d) Alternative Procedure. - If the ring fails to comply with the requirements of paragraph III-i(c) of this specification, the deflection-measuring apparatus shall be removed and then replaced. The difference between the deflections observed before and after this is done shall be not greater than the maxima specified in paragraphs III-I(a) and II-I(b) of this specification, under the loads there specified.

\section{METHOD OF CALIBRATION}

\section{COMPLETE CALIBRATION}

The following proving rings shall be calibrated in accordance with the requirements given in section II, Complete Calibration: Standards.

(a) Rings not previously calibrated at the National Bureau of

(b) Rings previously calibrated but not certified at their last calibrations. 1934.

(c) Rings previously calibrated but not certified since April 4,

(d) Rings which have been repaired or modified since their last calibrations.

2. RECALIBRATION

The following proving rings shall be calibrated in accordance with the requirements given in section III, Recalibration:

(a) Rings certified at their last calibrations provided such calibrations have been made since April 4, 1934 and provided the rings have not been repaired or modified since their last calibrations.

\section{LOADS IOT EXCEEDING 110,000 LB}

For loads not excecding 110,000 lb proving rings shall be calibrated by applying dead weights known to within 0.02 percent. 


\section{LOADS EXCEEDING 110,000 LB}

For loads exceeding 110,000 1b the applied load shall be known to within 0.1 percent.

\section{LOADING , PROCEDURE}

All proving rings shall be calibrated under increasing loads. Compressive loads, except as provided. in paragraph II-5(d), shall be applied to the lower boss of the ring through a plane, hardened steel bearing block and to the upper boss either through a ball or a soft steel block. Tensile loads shall be applied to the ring through the pulling rods provided with the ring.

\section{TEMPERATURE CORRECTION}

To compensate for temperature changes which occur during calibration, the deflections of a proving ring shall be corrected for temperature using the formula

$$
a_{70}=a_{t} \quad[1+K(t-70)]
$$

where $\mathrm{d}_{70}=\underset{\text { Fahrenheit }}{\text { deflection }}$ of ring for a temperature of 70 degrees

$$
\mathrm{d}_{t}=\underset{\text { Fahrenheit }}{\text { deflcction of ring for a temperature of } t \text { degrees }}
$$

$\mathrm{K}$ = temperature coefficient of Young's Nodulus of Elasticity

$t$ = temperature, degrees Fahrenheit, during test

The coefficient $K$ depends upon the chemical composition of the steel of which the ring is made and its heat treatment. For steels having a total alloying content not exceeding five percent the value $K=-0.00015$ per degree Fahrenheit is sufficiently accurate. For some other steels values of 1 have been found ranging from -0.00011 to -0.00024 . When a proring ring is submitted for calibration, the value of is ahall be furrich od this Bureau by the person submitting the ring or by the manufuturer of the ring. 


\section{METHOD OF REPORTING RESULTS}

\section{CERTIFICATES}

(a) Certificate of Calibration. - For rings which comply with the requirements of section II of this specification a certifieate of calibration will be issued including a calibration graph showing the calibration factor as a function of the ring deflection.

(b) Certificate of Recalibration. - For rings which comply with paragraphs III-I(a), III-I(b), and III-I(c), or with paragraphs III-I(a), III-I(b), and III-I(d), a certificate of recalibration will be issued including a calibration graph showing the calibration factor as a function of the ring deflection.

\section{REPORTS}

For rings which do not comply with the requirements of this specification a report will be issued giving the results in the form of a table and stating wherein the ring fails to comply with this specification. 